\title{
Preconditioning with Bright Light Evokes a Protective Response against Light Damage in the Rat Retina
}

\author{
Changdong Liu, ${ }^{1}$ Min Peng, ${ }^{1}$ Alan M. Laties, ${ }^{1}$ and Rong Wen ${ }^{1,2}$ \\ Departments of ${ }^{1}$ Ophthalmology and ${ }^{2} \mathrm{Cell}$ and Developmental Biology, University of Pennsylvania, School of Medicine, \\ Philadelphia, Pennsylvania 19104
}

\begin{abstract}
Constant exposure to bright light induces photoreceptor degeneration and at the same time upregulates the expression of several neurotrophic factors in the retina. At issue is whether the induced neurotrophic factors protect photoreceptors. We used a preconditioning paradigm to show that animals preconditioned with bright light became resistant to subsequent light damage. The preconditioning consisted of a 12-48 hr preexposure, followed by a $48 \mathrm{hr}$ "rest phase" of normal cyclic lighting. The greatest protection was achieved by a $12 \mathrm{hr}$ preexposure. Preconditioning induces a prolonged increase in two endogenous neurotrophic factors: basic fibroblast growth factor (bFGF) and ciliary neurotrophic factor (CNTF). It also
\end{abstract}

stimulates the phosphorylation of extracellular signal-regulated protein kinases (Erks) in both photoreceptors and Müller cells. These findings indicate that exposure to bright light initiates two opposing processes: a fast degenerative process that kills photoreceptors and a relatively slower process that leads to the protection of photoreceptors. The extent of light damage, therefore, depends on the interaction of the two processes. These results also suggest a role of endogenous bFGF and CNTF in photoreceptor protection and the importance of Erk activation in photoreceptor survival.

Key words: photoreceptor; Müller cell; light damage; degeneration; bFGF; CNTF; Erk; retina; rat
Noell and coworkers reported in 1966 that unremitting exposure to visible light, even at low irradiance levels, induced photoreceptor degeneration in albino rats. Although the exact mechanism is still not fully understood, this model of induced photoreceptor degeneration has been used widely to study the capability of photoreceptor protection by antioxidants (Organisciak and Winkler, 1994), neurotrophic factors (Faktorovich et al., 1992; LaVail et al., 1992), and agents that induce endogenous neurotrophic factors (Wen et al., 1996).

Recent studies provide evidence that endogenous neurotrophic factors protect photoreceptors from degeneration. For example, photoreceptors near a wound site are protected from light damage (Faktorovich et al., 1992; Wen et al., 1995). The injuryinduced photoreceptor protection is accompanied by a dramatic increase in the expression of basic fibroblast growth factor (bFGF) and ciliary neurotrophic factor (CNTF) surrounding the wound (Wen et al., 1995). These findings lead to a hypothesis that the retina responds to injury by upregulating neurotrophic factors to protect retinal cells and to accelerate repair and wound healing (Wen et al., 1995). Consistent with the hypothesis are the observations that retinal bFGF and CNTF are elevated in animals undergoing inherited retinal degenerations (Gao and Hollyfield, 1995) or light damage (Steinberg et al., 1995; Gao and Hollyfield, 1996).

Despite the upregulation of neurotrophic factors, severe loss of photoreceptors occurs in inherited or light-induced retinal degeneration. This raises a question as to whether these endogenous

Received Oct. 27, 1997; revised Dec. 4, 1997; accepted Dec. 5, 1997.

This work was supported by the Foundation Fighting Blindness and by a grant from the Paul and Evanina Mackall Foundation Trust. R.W. is a recipient of a Research to Prevent Blindness Career Development Award.

Correspondence should be addressed to Dr. Rong Wen, Department of Ophthalmology, D-603 Richards Building, University of Pennsylvania, School of Medicine, Philadelphia, PA 19104

Copyright (C) 1998 Society for Neuroscience $\quad 0270-6474 / 98 / 181337-08 \$ 05.00 / 0$ factors really protect photoreceptors. One possible explanation is that these factors do protect photoreceptors to some extent. In their absence photoreceptor loss would be more severe, yet in the presence of progressive photoreceptor degeneration, such putative protection is hard to demonstrate.

In the present work we used a preconditioning paradigm to detect the putative protection. The preconditioning consisted of exposure to bright light, followed by a "rest phase" in normal cyclic light. Animals so preconditioned displayed a remarkable resistance to light damage. The preconditioning resulted in a prolonged expression of bFGF and CNTF in the retina. It also activated extracellular signal-regulated protein kinases (Erks) in both photoreceptors and Müller cells. These findings provide evidence that exposure to bright light evokes a response that protects photoreceptors and suggest that neurotrophic factors likely mediate the protection.

\section{MATERIALS AND METHODS}

Animals and light exposure. Male Sprague Dawley rats (2-3 months old) were used in all experiments. Animals were kept in a 12:12 hr light/dark cycle at an in-cage illuminance of $<10$ candelas ( $1 \mathrm{~cd}=10.76 \mathrm{lux}$ ) for at least $7 \mathrm{~d}$ before the experiments. Preexposure to bright light was performed in a constant-light room of white fluorescent light in which the in-cage illuminance was $115-130 \mathrm{~cd}$. Photoreceptor degeneration (light damage) was induced by exposing animals to the same intensity continuously for $7 \mathrm{~d}$. The in-cage temperature was kept at $20-22^{\circ} \mathrm{C}$.

Histological evaluation of photoreceptor preservation. Animals were killed by $\mathrm{CO}_{2}$ overdose, immediately followed by vascular perfusion with mixed aldehydes (LaVail and Battelle, 1975). Eyes were embedded in an Epon/Araldite mixture and sectioned at $1 \mu \mathrm{m}$ thickness to display the entire retina along the vertical meridian of the eye (LaVail and Battelle, 1975). Photoreceptor preservation was assessed by light microscopy, using a scoring system to account for the well known nonuniform distribution of light damage across the retina and, in each retinal region, the number of surviving photoreceptor nuclei as well as the condition of the inner and outer segments of photoreceptors. The system used a five point scale, with the score for normal retina being five and the most severe loss of photoreceptors being one (Wen et al., 1996). Each tissue section was 


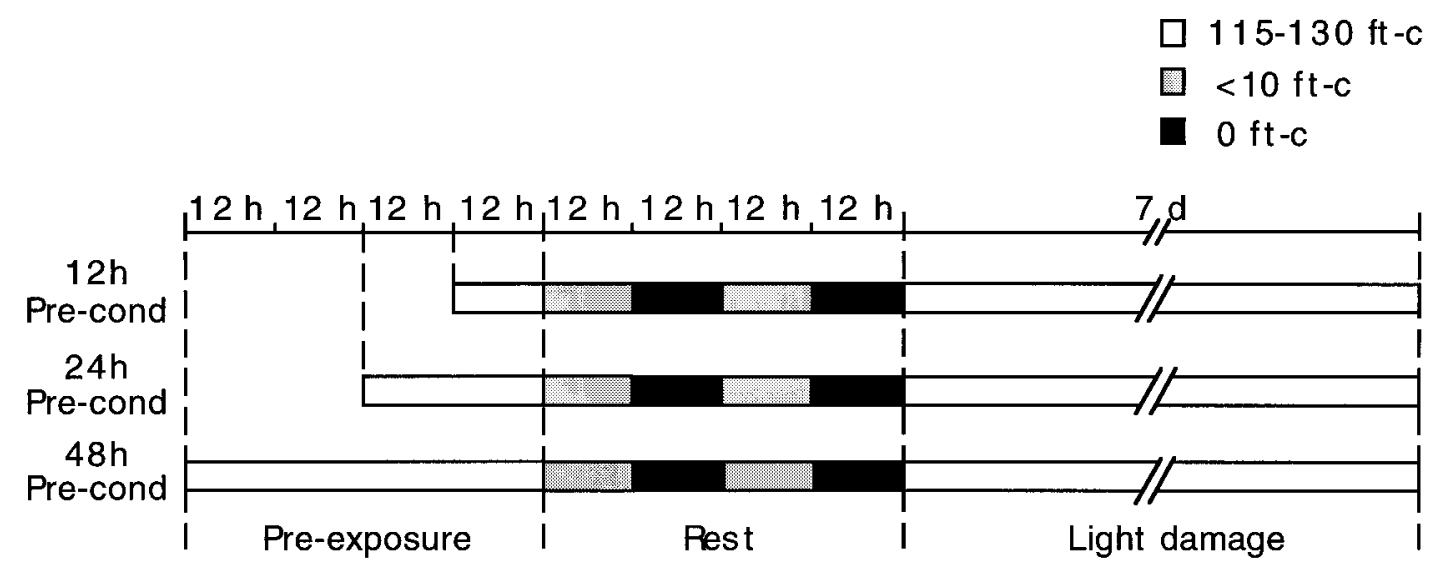

Figure 1. Schematic illustration of the preconditioning paradigm. Animals were preexposed to $115-130 \mathrm{~cd}$ of light continuously for 12 , 24, or 48 hr and then returned to normal cyclic light of $12 \mathrm{hr}$ light $(<10 \mathrm{~cd}) / 12 \mathrm{hr}$ dark cycle for $48 \mathrm{hr}$. Light damage was induced by a $7 \mathrm{~d}$ constant light exposure at $115-130 \mathrm{~cd}$.

assessed independently by three scientists equally familiar with the scoring criteria.

RNA preparation and Northern blot analysis. Retinas were dissected, snap-frozen in liquid nitrogen, and stored at $-80^{\circ} \mathrm{C}$. Total RNA was obtained from pooled retinas with an RNeasy Total RNA Kit (Qiagen, Chatsworth, CA) according to the manufacturer's instructions. Northern blot analyses were performed as previously described (Wen et al., 1995). Briefly, total RNA (20 $\mu \mathrm{g}$ of each sample) was electrophoresed on $1 \%$ agarose formaldehyde gels and transferred to a nylon membrane (Hybond-N, Amersham, Arlington Heights, IL). Blots were prehybridized for $4 \mathrm{hr}$ at $50^{\circ} \mathrm{C}$. Random primed ${ }^{32} \mathrm{P}$-labeled cDNA probes for rat bFGF [gift of Dr. A. D. Baird, Whittier Institute for Diabetes and Endocrinology, La Jolla, CA; (Shimasaki et al., 1988)], rat CNTF [gift of Dr. N. Y. Ip, Regeneron Pharmaceuticals, Tarrytown, NY (Stöckli et al., 1989)], or rat 18s rRNA [gift of Dr. D. Schlessinger, Washington University, St. Louis, MO; (Bowman et al., 1981)] were added to the hybridization buffer $\left(10^{6} \mathrm{cpm} / \mathrm{ml}\right)$ and hybridized at $50^{\circ} \mathrm{C}$ overnight. Blots were exposed to a Storage Phosphor Screen (Molecular Dynamics, Sunnyvale, CA), and data were digitized by scanning the phosphor screen with a PhosphorImager System (Molecular Dynamics).

Protein preparation and immunoblotting analysis. Retinas were dissected, snap-frozen in liquid nitrogen, and stored at $-80^{\circ} \mathrm{C}$. Pooled retinas were homogenized, and total protein $(100 \mu \mathrm{g} /$ lane $)$ was electrophoresed on polyacrylamide gels and transferred to nitrocellular membranes (Bio-Rad Labs, Hercules, CA). Blots were examined by immunoblotting analysis, using the following antibodies: rabbit anti-bFGF polyclonal antibodies (Santa Cruz Biotechnology, Santa Cruz, CA), chicken anti-CNTF polyclonal antibodies (Promega, Madison, WI), rabbit anti-p44/42 phospho-Erk polyclonal antibodies (Promega), and rabbit anti-p44/42 Erk polyclonal antibodies (New England Biolabs, Beverly, MA). Signals were visualized with an ECL kit (Amersham, Arlington Heights, IL) and recorded on Hyperfilm (Amersham).

Immunocytochemistry. Eyes, removed from $4 \%$ paraformaldehydeperfused animals, were cryoprotected with $20 \%$ sucrose, frozen in Tissue-Tek OCT compound (Miles, Elkhart, IN) in powdered dry ice, and stored at $-80^{\circ} \mathrm{C}$. Cryosections of $10 \mu \mathrm{m}$ were cut through the entire retina along the vertical meridian and thaw-mounted onto Super Frost Plus glass slides (Fisher Scientific, Pittsburgh, PA). For immunostaining, sections were rinsed in PBS and permeabilized with $0.1 \%$ Triton X-100 for $30 \mathrm{~min}$. The sections were incubated with blocking solution (10\% goat serum in PBS) for $1 \mathrm{hr}$, followed by a $2 \mathrm{hr}$ incubation with anti-phosphoErk (1:800 dilution) antibodies at room temperature. Immunoreactivity was visualized with an $\mathrm{ABC}$ kit (Vector Laboratories, Burlingame, $\mathrm{CA}$ ) and a TSA-Direct kit (NEN-Life Science Products, Boston, MA), according to the manufacturers' instructions.

\section{RESULTS}

\section{Preconditioning protects photoreceptors from light damage}

The preconditioning paradigm is illustrated schematically in Figure 1 . For preconditioning, animals were preexposed for 12,24 , or
$48 \mathrm{hr}$ to an intensity of $115-130 \mathrm{~cd}$. On termination of the preexposure, animals were returned to normal cyclic light conditions for a "rest phase" of $48 \mathrm{hr}$. To induce light damage, we placed preconditioned animals to constant light of $115-130 \mathrm{~cd}$ for $7 \mathrm{~d}$ immediately after the rest phase. Controls received constant light of $115-130 \mathrm{~cd}$ for $7 \mathrm{~d}$ without any preconditioning.

Figure 2 shows representative sections of superior retinas from a normal animal (Fig. $2 A$ ) and animals that received constant light exposure (115-130 cd) for $7 \mathrm{~d}$ without (Fig. 2B) or with (Fig. $2 C)$ a $12 \mathrm{hr}$ preconditioning. Severe photoreceptor degeneration was observed in animals without preconditioning (Fig. 2B). In these retinas the outer nuclear layer $(\mathrm{ONL})$, where photoreceptor nuclei reside, was reduced from 10-11 rows of nuclei in normal animals (Fig. $2 A$ ) to one to two rows (Fig. $2 B$ ). There was almost a complete absence of photoreceptor inner segments, and the remaining outer segments formed large rounded or oblong profiles (Fig. $2 B$ ). In the preconditioned animals, however, the photoreceptor degeneration was much less severe (Fig. $2 C$ ). There were, on average, five to seven rows of photoreceptor nuclei in the ONL. The inner segments were present, although shorter than normal. The outer segments were better preserved; many also showed rounded and oblong profiles (Fig. 2C).

The degree of photoreceptor preservation was scored. In animals without preconditioning the degree of photoreceptor preservation after $7 \mathrm{~d}$ of constant light exposure is $1.10 \pm 0.17$ (mean $\pm \mathrm{SD}, n=12$ ). In animals given a $12 \mathrm{hr}$ preconditioning, the score is $3.17 \pm 0.22(n=12)$ and $2.96 \pm 0.21(n=12)$ for those that received a $24 \mathrm{hr}$ conditioning. The score for animals of $48 \mathrm{hr}$ preconditioning is $1.91 \pm 0.52(n=12)$ (Fig. 3$)$.

The lesser protection in animals that received longer preconditioning suggests that some light damage resulted from the preexposure. To assess the possible light damage induced by preconditioning itself, we exposed animals to $115-130 \mathrm{~cd}$ for 12,24 , or $48 \mathrm{hr}$ and returned them to normal cyclic light for $9 \mathrm{~d}$ (to match the $2 \mathrm{~d}$ of the rest phase and the $7 \mathrm{~d}$ of constant light exposure). Figure 4 shows representative superior retinas from these animals. For those receiving a $12 \mathrm{hr}$ exposure, there was no obvious morphological change in their photoreceptors (Fig. $4 A)$. The outer and inner segments of photoreceptors appeared similar to those of normal animals (see Fig. $2 A$ ). No measurable loss of photoreceptor nuclei was found in the $\mathrm{ONL}$ (Fig. $4 A$ ). In contrast, $24 \mathrm{hr}$ of exposure led to disorganization 

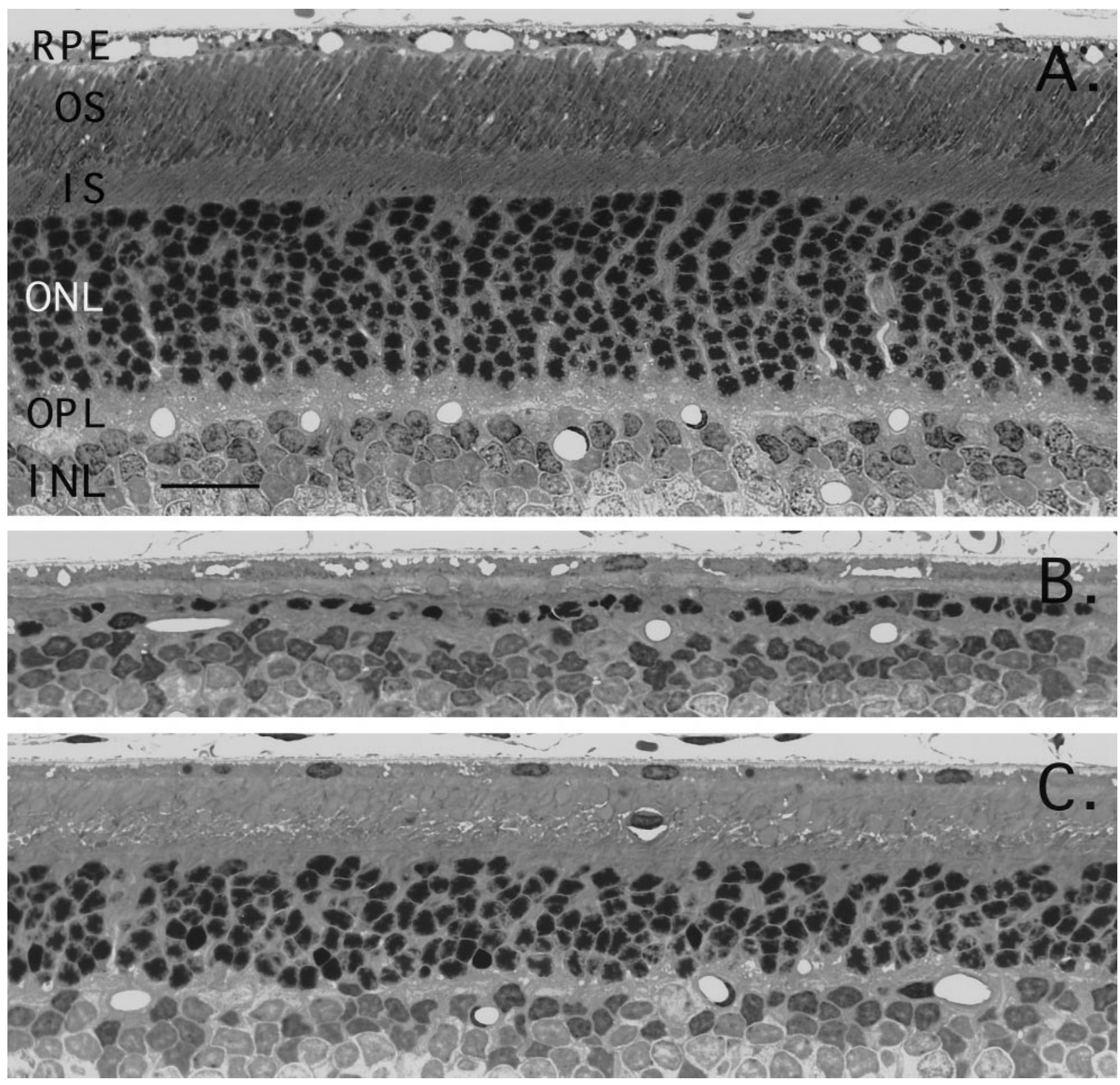

Figure 2. Protection of photoreceptors by $12 \mathrm{hr}$ preconditioning. $A$, Normal retina (superior region) of a rat kept in cyclic light. The photoreceptor outer segments $(O S)$ are opposed to the retinal pigment epithelium $(R P E)$, distinct photoreceptor inner segments $(I S)$ are present, and the outer nuclear layer $(O N L)$ consists of 10-11 rows of photoreceptor cell nuclei. B, Retina of a rat exposed to $7 \mathrm{~d}$ of constant light without preconditioning (superior region). The $O N L$ is reduced to one to two rows of nuclei; the inner segments are missing or are reduced to short stumps; the few remaining outer segments are in the form of large rounded or oblong profiles. $C$, Superior retina of a rat that received a $12 \mathrm{hr}$ preconditioning and then was exposed to $7 \mathrm{~d}$ of constant light. The $O N L$ shows six to seven rows of nuclei; the inner segments are shorter than normal, and the outer segments, although better preserved than in $B$, are disorganized, many showing rounded and oblong profiles. Toluidine blue stain was used. $O P L$, Outer plexiform layer; $I N L$, inner nuclear layer. Scale bar, $20 \mu \mathrm{m}$.

of the outer segments and enlargement of their tips. There was measurable shortening of the inner segments, and the ONL was reduced by one to two rows of cell nuclei (Fig. 4B). Significant light damage was evident in retinas after $48 \mathrm{hr}$ of exposure (Fig. 4C). The outer segments of photoreceptors exhibited rounded and oblong profiles. There was a significant shortening of the inner segments. Moreover, the ONL was reduced to six to seven rows of nuclei. In 24 and $48 \mathrm{hr}$ exposed animals, the damage to the inferior retinas was slightly greater than that superiorly (data not shown).

\section{Preconditioning induces prolonged expression of bFGF and CNTF}

Previous work showed that, among several neurotrophic factors, only the expression of bFGF and CNTF was induced by exposure to constant light (Steinberg et al., 1995). We therefore examined the mRNA and protein expression of these two neurotrophic factors. Northern blotting analysis was used to determine the mRNA expression of bFGF and CNTF. Retinas from animals exposed to bright light for $12 \mathrm{hr}$ were collected at $0,0.5,1,2,4,7$, 


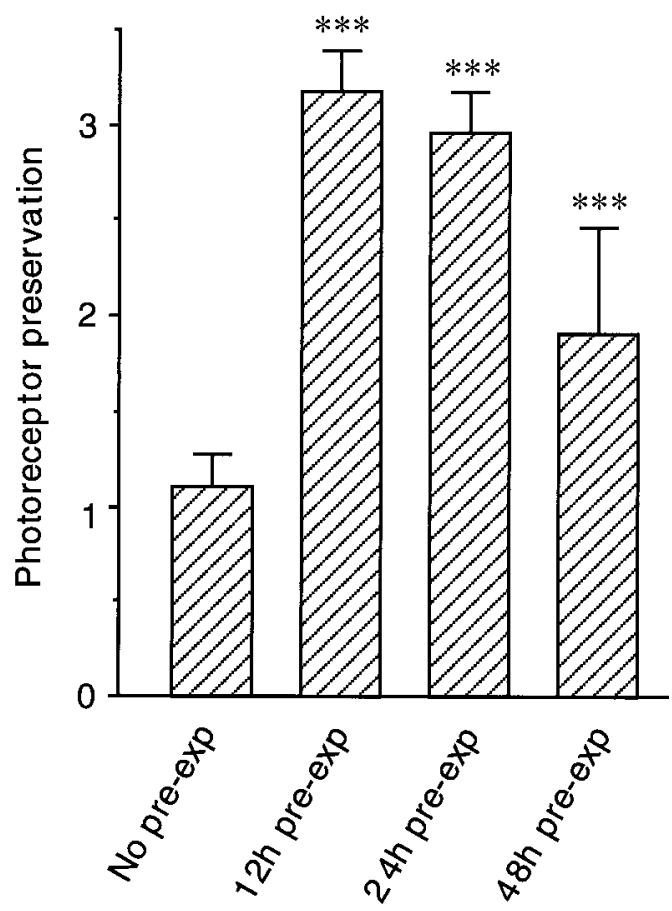

Figure 3. Degree of photoreceptor preservation in retinas with or without preconditioning. Preservation of photoreceptors was determined by weighting the overall thickness of the ONL and the integrity and organization of the inner and outer segments in a retina. In animals without preconditioning, the degree of photoreceptor preservation after $7 \mathrm{~d}$ of constant light exposure was $1.10 \pm 0.17$ (mean $\pm \mathrm{SD} ; n=12)$. In animals that had received a $12 \mathrm{hr}$ preexposure, the score was $3.17 \pm 0.22(n=12)$; for $24 \mathrm{hr}$ preexposure the score was $2.96 \pm 0.21(n=12)$ and $1.91 \pm 0.52$ $(n=12)$ for the $48 \mathrm{hr}$ preexposure. ${ }^{* *} p<0.001$; Student's $t$ test.

or $10 \mathrm{~d}$ after exposure. A major $7.0 \mathrm{~kb}$ transcript was detected by using probes complementary to mRNA encoding for bFGF (Fig. 5 , top). A significant increase in bFGF mRNA was present by the end of the exposure (day 0 ); the maximum was reached within $1 \mathrm{~d}$ after exposure. Although the expression then slowly declined, it was still at a relatively high level $10 \mathrm{~d}$ after exposure. CNTF mRNA was detected as a single band of $1.2 \mathrm{~kb}$ (Fig. 5 , middle). An increase in CNTF mRNA was first detectable $0.5 \mathrm{~d}$ after exposure, reaching its peak in $4 \mathrm{~d}$. The level of $18 \mathrm{~s}$ rRNA was assessed as a control for RNA loading (Fig. 5, bottom).

The protein expression of bFGF and CNTF was determined by immunoblotting analyses. bFGF protein was detected as three bands at $24,22.5$, and $18 \mathrm{kDa}$. Its expression showed a progressive increase from day 1 onward (Fig. 6, top). Increase in CNTF protein $(26 \mathrm{kDa})$ was first observed at $2 \mathrm{~d}$, and it reached a maximum in $4 \mathrm{~d}$, slowly declining thereafter (Fig. 6, bottom).

\section{Preconditioning induces phosphorylation/activation of Erk in photoreceptors and Müller cells}

We next investigated the activation state of Erks by immunoblotting, using anti-phospho-Erk antibodies to recognize specifically the dually phosphorylated form of Erk1 (p44) and Erk2 (p42). As shown in Figure 7 (top), a dramatic increase in Erk phosphorylation was observed immediately after a $12 \mathrm{hr}$ exposure to 115 $130 \mathrm{~cd}$, which lasted at least $12 \mathrm{hr}$. The protein levels of the two Erks were not altered by the exposure (see Fig. 6, bottom).

The induced phospho-Erks in the retina were localized by immunocytochemistry. As shown in Figure 8, in the normal retina only a few cells in the inner nuclear layer were phospho-
Erk-positive; at least one could be identified as a Müller cell, its typical radial processes positively stained (Fig. 8A). After a $12 \mathrm{hr}$ exposure to $115-130 \mathrm{~cd}$, some inner segments of photoreceptors stained positively (Fig. 8B, arrowheads). In addition, there was a dramatic increase in phospho-Erk-positive cell bodies in the inner nuclear layer (Fig. 8B). In most of these cells, positive immunoreactivity also was detected in processes that extended to the inner and the outer limiting membranes, identifying them as Müller cells (Fig. 8B).

\section{DISCUSSION}

We have used a preconditioning paradigm to reveal a remarkable ability of the retina to mount a protective response for photoreceptors. The preconditioning paradigm is composed of two parts: a short preexposure to bright light that initiates the protective response and a $48 \mathrm{hr}$ "rest phase" under normal cyclic light that allows the protective response to develop. Retinas so preconditioned exhibit a substantial resistance to light damage. These results indicate that exposure to bright light initiates two opposing processes in the retina: a degenerative process that kills photoreceptors and a protective response that protects them. The time courses of the two processes are quite different. The degenerative one is faster, causing accelerated death of photoreceptors in the first $2 \mathrm{~d}$ of exposure, especially during the second day of exposure. The protective response is slower and requires $2 \mathrm{~d}$ to develop fully. Thus, during the first $2 \mathrm{~d}$ of continuous exposure to bright light (115-130 cd in the present work), massive photoreceptor death occurs before the protective response is fully developed.

Since its discovery in 1966, continued research efforts have provided a wealth of information on light damage (for review, see Organisciak and Winkler, 1994; Rapp, 1995). It already is known that susceptibility to light damage relates to light intensity of the rearing environment of animals (Penn and Anderson, 1994). The relatively low light damage susceptibility of animals raised in bright lighting environment has been explained in part by increased antioxidant levels found in retinas of these animals (Penn et al., 1987). Recently, the photoreceptor protection properties of several neurotrophic factors, including bFGF and CNTF, have been clearly demonstrated against light damage in rats, as well as in the RCS (Royal College of Surgeons) rats bearing an inherited photoreceptor degeneration (Faktorovich et al., 1990, 1992; LaVail et al., 1992). In addition, an upregulation of endogenous bFGF and CNTF observed in mechanically injured retina is believed to be responsible for injury-induced photoreceptor protection (Wen et al., 1995). Increased bFGF or CNTF expression also is found in inherited and induced retinal degenerative animal models (Gao and Hollyfield, 1995, 1996; Steinberg et al., 1995). In the present work we show that a $12 \mathrm{hr}$ exposure to bright light induces a large and prolonged increase in bFGF and CNTF expression. Moreover, significant elevation of the two proteins coincides with the $2 \mathrm{~d}$ "rest phase" of the preconditioning paradigm. Together, these findings strongly suggest that endogenous neurotrophic factors take part in the preconditioning-induced photoreceptor protection.

Protection of photoreceptors by preconditioning exposure resembles "conditioning lesion" effects previously recognized in the brain and the peripheral nervous system. An initial (conditioning) lesion facilitates tissue recovery from a subsequent (test) lesion (McQuarrie et al., 1977; Nieto-Sampedro et al., 1984; Perez-Polo et al., 1990). The accelerated recovery from the second lesion has been attributed to an increase in synthesis and the secretion of 


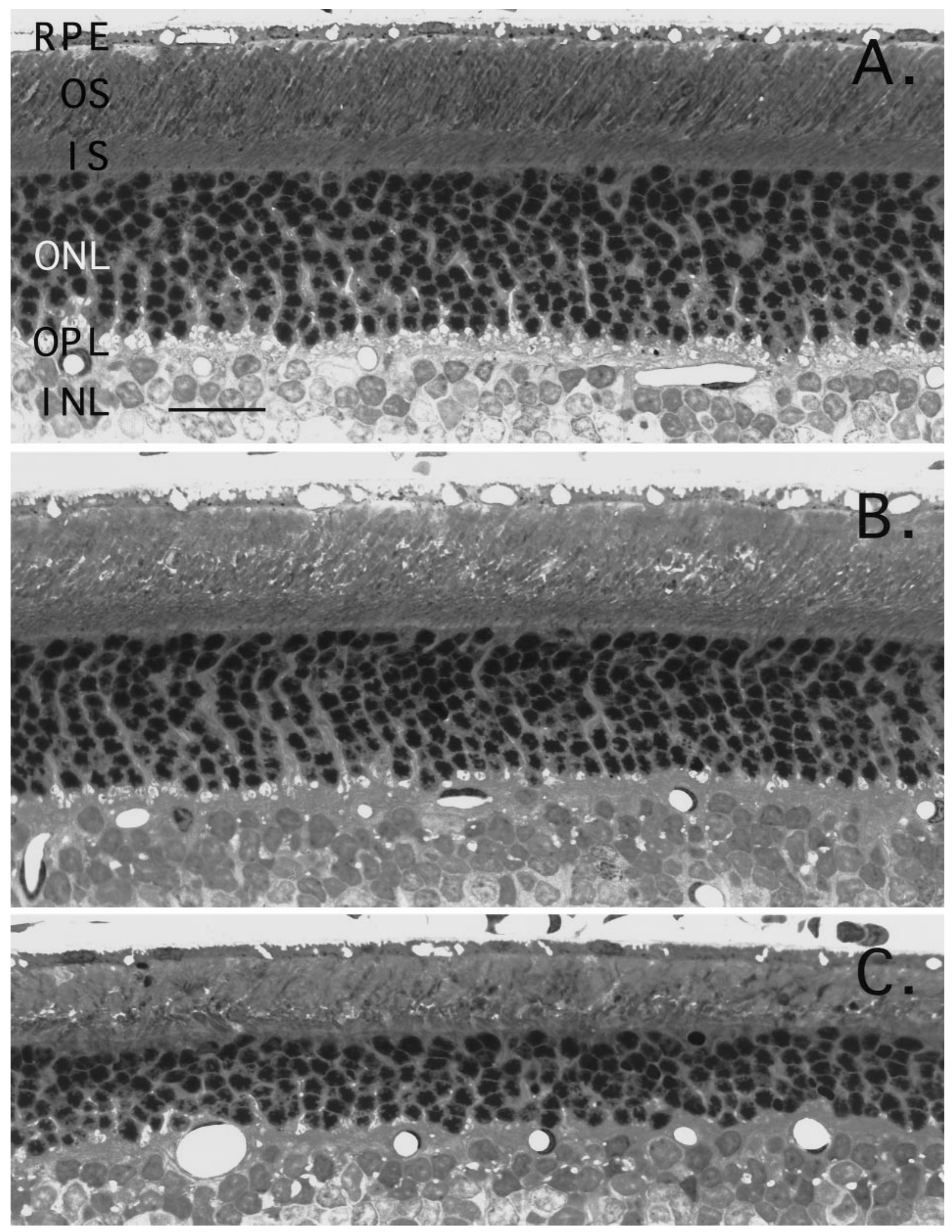

Figure 4. Light damage by preexposure. $A$, Superior retina of a rat received a $12 \mathrm{hr}$ exposure. Outer and inner segments of photoreceptors appear similar to normal control (see Fig. $2 A$ ). There is no apparent loss of photoreceptor nuclei in the $O N L$. B, Superior retina from a rat of 24 hr exposure. Outer segments of photoreceptors are disorganized, and their tips are enlarged. Inner segments are shortened. The $O N L$ is reduced by one to two rows of cell nuclei. $C$, Retina of a rat exposed to constant light for $48 \mathrm{hr}$. Outer segments of photoreceptors clearly are damaged, showing rounded and oblong profiles. The inner segments are shortened significantly. The $O N L$ is reduced to six to seven rows of nuclei. Abbreviations, staining, and scale bar are the same as in Figure 1. 


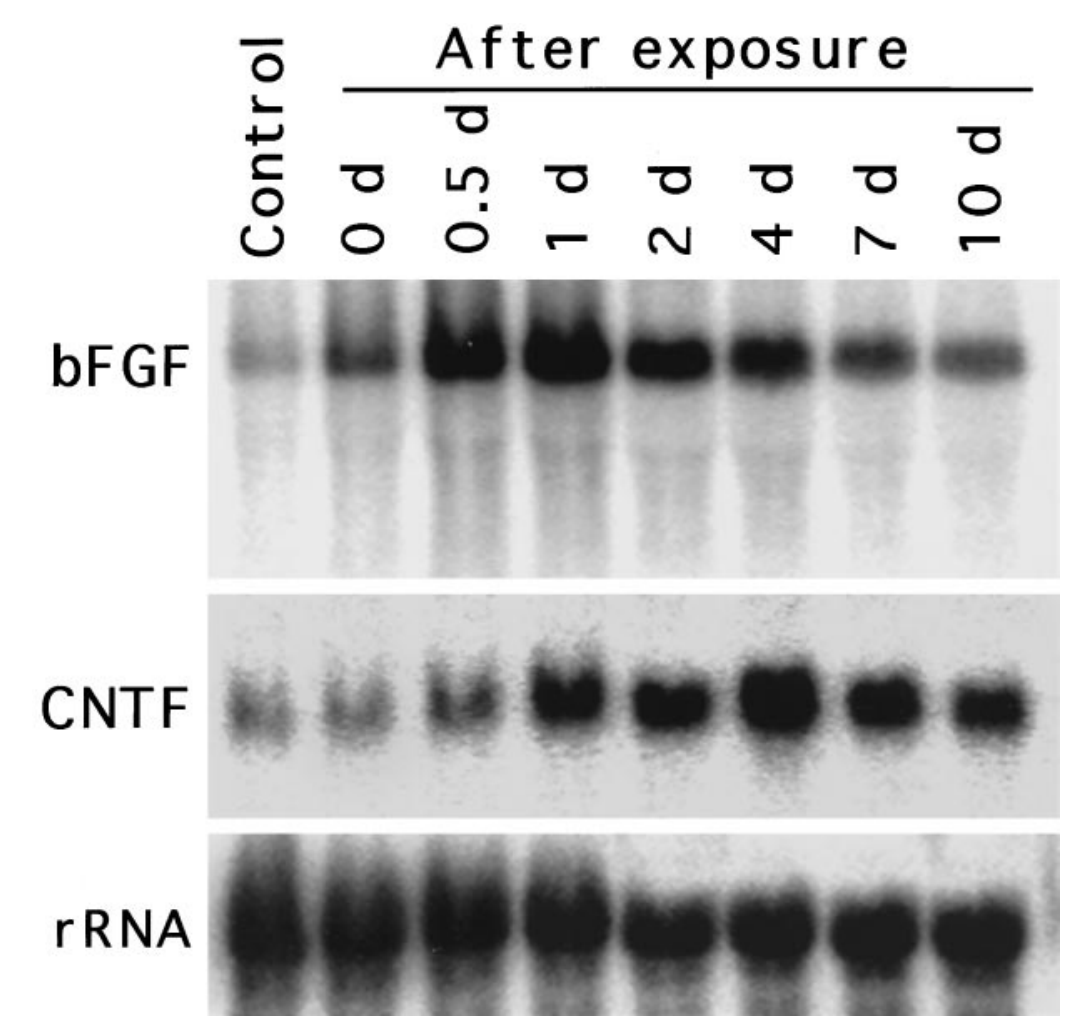

Figure 5. Expression of bFGF and CNTF mRNAs after 12 $\mathrm{hr}$ exposure. A Northern blot was hybridized with probes for bFGF and rehybridized with probes for CNTF. A major $7.0 \mathrm{~kb}$ transcript was detected in all lanes (top). The same blot was rehybridized with probes for CNTF mRNA. CNTF transcript was detected as a $1.2 \mathrm{~kb}$ band (middle). The time after the 12 $\mathrm{hr}$ preexposure is indicated at the top of each lane. The blot finally was rehybridized with probes for 18s rRNA (bottom).

Figure 6. Expression of bFGF and CNTF protein after $12 \mathrm{hr}$ exposure. Immunoblotting analyses were performed to assess bFGF and CNTF proteins after a $12 \mathrm{hr}$ preexposure. Three isoforms of bFGF protein of $24,22.5$, and $18 \mathrm{kDa}$ were detected. CNTF protein was found as a single band at $26 \mathrm{kDa}$. The time after the $12 \mathrm{hr}$ preexposure is indicated at the top of each lane.

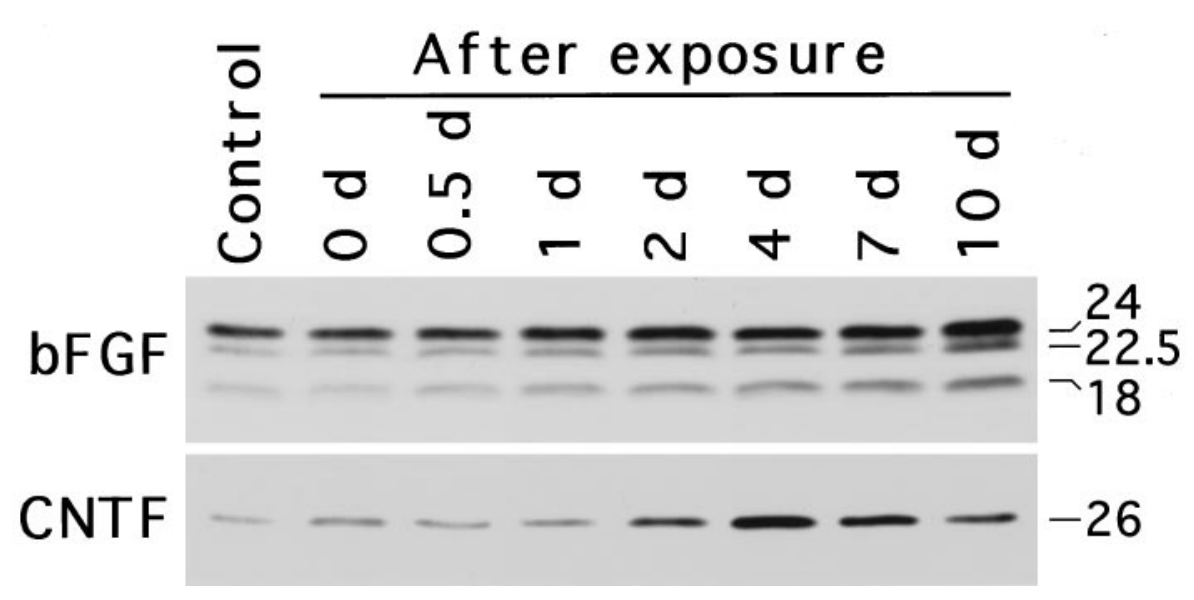

neurotrophic factors stimulated by the conditioning lesion (NietoSampedro and Cotman, 1985), such as bFGF (Finklestein et al., 1988; Frautschy et al., 1991; Logan et al., 1992) or CNTF (Ip et al., 1993).

Many neurotrophic factors, including NGF, BDNF, and bFGF, exert their effects by interacting with receptor tyrosine kinases and by activating the Ras/Raf/MAPK (mitogen-activated protein kinase) pathway. Activation of Erks is well recognized as an essential step in the Ras/MAPK cascade (Davis, 1993; Nishida and Gotoh, 1993; Leevers and Marshall, 1995). Some stress signals also use this signaling pathway for Erk activation. For example, ultraviolet irradiation induces phosphorylation of Erks in HeLa cells via growth factor receptors and a Ras-dependent pathway (Sachsenmaier et al., 1994). $\mathrm{H}_{2} \mathrm{O}_{2}$ rapidly induces Erk phosphorylation in National Institutes of Health 3T3 and PC 12 cells also via a Ras-dependent pathway (Guyton et al., 1996). In addition, inhibition of $\mathrm{H}_{2} \mathrm{O}_{2}$-induced Erk activation greatly increases the susceptibility of cells to $\mathrm{H}_{2} \mathrm{O}_{2}$ toxicity (Guyton et al.,
Figure 7. Phosphorylation of Erks after $12 \mathrm{hr}$ exposure. Immunoblotting analyses were performed to detect Erk phosphorylation in the retina. Dually phosphorylated Erks ( $p p$-Erk) or Erk proteins $(E r k)$ were detected as two bands at 44 and $42 \mathrm{kDa}$. The time after the $12 \mathrm{hr}$ preexposure is indicated at the top of each lane. 

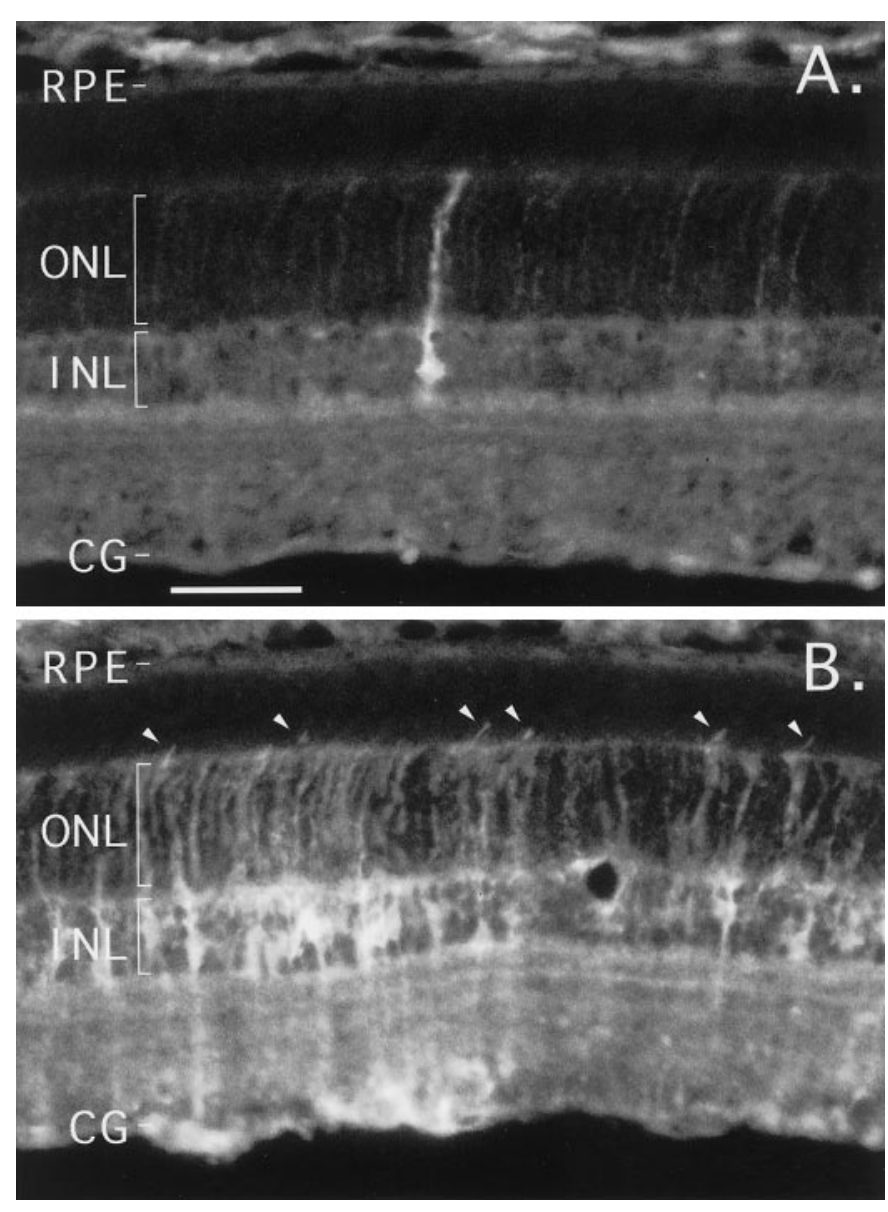

Figure 8. Localization of induced Erk phosphorylation. Phospho-Erk was visualized by immunostaining, using phospho-Erk-specific antibodies in normal retina $(A)$ and in a retina from an animal after $12 \mathrm{hr}$ light exposure $(B)$. A few phospho-Erk-positive cells were labeled in the normal retina. At least one with a typical radial process can be identified as a Müller cell. After bright light exposure, a number of photoreceptor inner segments became phospho-Erk-positive (arrowheads). Many cells in the inner nuclear layer were labeled also. Processes extending to the inner and outer limiting membranes identified them as Müller cells. RPE, Retinal pigment epithelium; $O N L$, outer nuclear layer; $I N L$, inner nuclear layer; $G C$, ganglion cell layer. Scale bar, $50 \mu \mathrm{m}$.

1996), indicating that Erk activation is critical for cell survival. Because a $12 \mathrm{hr}$ exposure to $115-130 \mathrm{~cd}$ of light induces a significant and prolonged increase in Erk phosphorylation in both photoreceptors and Müller cells, Erk activation likely is involved in mediating photoreceptor protection. Of special pertinence, two recent reports describe an increase in Erk phosphorylation in ischemic injury in rat and cat retinas (Hayashi et al., 1996, 1997), again indicating that Erk activation represents an important step in retinal response to injury.

Müller cells are believed to act as housekeepers, maintaining the integrity and the normal function of the retina. They are also important for photoreceptor survival (Wen et al., 1995). The present demonstration of increased Erk phosphorylation suggests that Müller cells play a role in preconditioning-induced photoreceptor protection.

The present report highlights an endogenous protective system in the retina. Aspects of this system previously have been glimpsed under several conditions (Faktorovich et al., 1990, 1992; Wen et al., 1995). A common underlying mechanism is indicated by the similarity of induced expression of neurotrophic factors by exposure to bright light (Steinberg et al., 1995) and by mechanical injury (Wen et al., 1995). Further investigation of such a mechanism could well have therapeutic potential for degenerative disorders of photoreceptors.

\section{REFERENCES}

Bowman LH, Rabin B, Schlessinger D (1981) Multiple ribosomal RNA cleavage pathways in mammalian cells. Nucleic Acids Res 9:4951-4966.

Davis RJ (1993) The mitogen-activated protein kinase signal transduction pathway. J Biol Chem 268:14553-14556.

Faktorovich EG, Steinberg RH, Yasumura D, Matthes MT, LaVail MM (1990) Photoreceptor degeneration in inherited retinal dystrophy delayed by basic fibroblast growth factor. Nature 347:83-86.

Faktorovich EG, Steinberg RH, Yasumura D, Matthes MT, LaVail MM (1992) Basic fibroblast growth factor and local injury protect photoreceptors from light damage in the rat. J Neurosci 12:3554-3567.

Finklestein SP, Apostolides PJ, Caday CG, Prosser J, Philips MF, Klagsbrun M (1988) Increased basic fibroblast growth factor (bFGF) immunoreactivity at the site of focal brain wounds. Brain Res 460:253-259.

Frautschy SA, Walicke PA, Baird A (1991) Localization of basic fibroblast growth factor and its mRNA after CNS injury. Brain Res 553:291-299.

Gao H, Hollyfield JG (1995) Basic fibroblast growth factor in retinal development: differential levels of bFGF expression and content in normal and retinal degeneration $(r d)$ mutant mice. Dev Biol 169:168-184.

Gao H, Hollyfield JG (1996) Basic fibroblast growth factor: increased gene expression in inherited and light-induced photoreceptor degeneration. Exp Eye Res 62:181-189.

Guyton KZ, Liu Y, Gorospe M, Xu Q, Holbrook NJ (1996) Activation of mitogen-activated protein kinase by $\mathrm{H}_{2} \mathrm{O}_{2} . \mathrm{J}$ Biol Chem 271:4138-4142.

Hayashi A, Koroma BM, Imai K, de Juan EJ (1996) Increase of protein tyrosine phosphorylation in rat retina after ischemia-reperfusion injury. Invest Ophthalmol Vis Sci 37:2146-2156.

Hayashi A, Imai K, Kim HC, de Juan EJ (1997) Activation of protein tyrosine phosphorylation after retinal branch vein occlusion in cats. Invest Ophthalmol Vis Sci 38:372-380.

Ip NY, Wiegand SJ, Morse J, Rudge JS (1993) Injury-induced regulation of ciliary neurotrophic factor mRNA in the adult rat brain. Eur J Neurosci 5:25-33.

LaVail MM, Battelle B-A (1975) Influence of eye pigmentation and light deprivation on inherited retinal dystrophy in the rat. Exp Eye Res 21:167-192.

LaVail MM, Unoki K, Yasumura D, Matthes MT, Yancopoulos GD, Steinberg RH (1992) Multiple growth factors, cytokines, and neurotrophins rescue photoreceptors from the damaging effects of constant light. Proc Natl Acad Sci USA 89:11249-11253.

Leevers S, Marshall C (1995) Extracellular signal-regulated kinases (Erks). In: Guidebook to the small GTPases (Zerial M, Huber LA, eds), pp 160-164. New York: Oxford UP.

Logan A, Frautschy SA, Gonzalez A-M, Baird A (1992) A time course for the focal elevation of synthesis of basic fibroblast growth factor and one of its high-affinity receptors ( $f l g$ ) following a localized cortical brain injury. J Neurosci 12:3828-3837.

McQuarrie IG, Grafstein B, Gershon MD (1977) Axonal regeneration in the rat sciatic nerve: effect of a conditioning lesion and of dbcAMP. Brain Res 132:443-453.

Nieto-Sampedro M, Cotman CW (1985) Growth factor induction and temporal order in central nervous system repair. In: Synaptic plasticity (Cotman CW, ed), pp 407-455. New York: Guilford.

Nieto-Sampedro M, Whittemore SR, Needels DL, Larson J, Cotman CW (1984) Survival of brain transplants is enhanced by extracts from injured brain. Proc Natl Acad Sci USA 81:6250-6254.

Nishida E, Gotoh Y (1993) The MAP kinase cascade is essential for diverse signal transduction pathways. Trends Biochem Sci 18:128-130.

Noell WK, Walker VS, Kang BS, Berman S (1966) Retinal damage by light in rats. Invest Ophthalmol Vis Sci 5:450-473.

Organisciak DT, Winkler BS (1994) Retinal light damage: practical and theoretical considerations. In: Progress in retinal and eye research, Vol 13 (Osborne N, Chader GS, eds), pp 1-29. Tarrytown, NY: Pergamon. Penn JS, Anderson RE (1994) Effects of light history on the rat retina. 
In: Progress in retinal and eye research, Vol 13 (Osborne N, Chader GS, eds), pp 75-98. Tarrytown, NY: Pergamon.

Penn JS, Naash MI, Anderson RE (1987) Effect of light history on retinal antioxidants and light damage susceptibility in the rat. Exp Eye Res 44:915-928.

Perez-Polo JR, Foreman PJ, Jackson GR, Shan D, Taglialatela G, Thorpe LW, Werrbach-Perez K (1990) Nerve growth factor and neuronal cell death. In: Molecular neurobiology (Bazan NG, ed), pp 57-90. Clifton, NJ: Humana.

Rapp LM (1995) Retinal phototoxicity. In: Handbook of neurotoxicology (Chang LW, Dyer RS, eds), pp 963-1003. New York: Dekker.

Sachsenmaier C, Radler-Pohl A, Zinck R, Nordheim A, Herrlich P, Rahmsdorf HJ (1994) Involvement of growth factor receptors in the mammalian UVC response. Cell 78:963-972.

Shimasaki S, Emoto N, Koba A, Mercado M, Shibata F, Cooksey K, Baird A, Ling N (1988) Complementary DNA cloning and sequencing of rat ovarian basic fibroblast growth factor and tissue distribution study of its mRNA. Biochem Biophys Res Commun 157:256-263.

Steinberg RH, Song Y, Cheng T, Matthes MT, Yasumura D, LaVail MM, Wen R (1995) Exposure to constant light upregulates the expression of bFGF, CNTF, FGFR-1, and GFAP mRNAs in the rat retina. Invest Ophthalmol Vis Sci 36:S637.

Stöckli KA, Lottspeich F, Sendtner M, Masiakowski P, Carroll P, Götz R, Lindholm D, Thoenen H (1989) Molecular cloning, expression, and regional distribution of rat ciliary neurotrophic factor. Nature 342:920-923.

Wen R, Song Y, Cheng T, Matthes MT, Yasumura D, LaVail MM, Steinberg RH (1995) Injury-induced upregulation of bFGF and CNTF mRNAs in the rat retina. J Neurosci 15:7377-7385.

Wen R, Cheng T, Li Y, Cao W, Steinberg RH (1996) $\alpha_{2}$-adrenergic agonists induce basic fibroblast growth factor expression in photoreceptors in vivo and ameliorate light damage. J Neurosci 16:5986-5992. 